\title{
The double-orifice technique in mitral valve repair: A simple solution for complex problems
}

Ottavio Alfieri, MD

Francesco Maisano, MD

Michele De Bonis, MD

Pier Luigi Stefano, MD

Lucia Torracca, MD

Michele Oppizzi, MD

Giovanni La Canna, MD

From the Division of Cardiac Surgery, IRCCS S. Raffaele Hospital, Milan, Italy.

Read at the Twenty-sixth Annual Meeting of The Western Thoracic Surgical Association, The Big Island, Hawaii, June 21-24, 2000.

Received for publication Oct 16, 2000; revisions requested Nov 13, 2000; revisions received April 9, 2001; accepted for publication April 30, 2001.

Address for reprints: Ottavio Alfieri, MD, Divisione di Cardiochirurgia, Ospedale $\mathrm{S}$ Raffaele, Via Olgettina 60, 20132, Milano, Italy (E-mail: ottavio.alfieri@hsr.it).

J Thorac Cardiovasc Surg 2001;122:674-81

Copyright (c) 2001 by The American Association for Thoracic Surgery

$0022-5223 / 2001 \$ 35.00+0 \quad \mathbf{1 2 / 6 / 1 1 7 2 7 7}$

doi:10.1067/mtc.2001.117277
Objective: The aim of this study is to report our results with the central doubleorifice technique used for the treatment of complex mitral valve lesions.

Methods: The central double-orifice repair has been used in 260 patients (mean age, $56 \pm 14.3$ years) over a period of 7 years. The mechanism responsible for mitral regurgitation was prolapse of both leaflets in 148 patients, prolapse of the anterior leaflet in 68 , prolapse of the posterior leaflet with annular calcification or other unfavorable features in 31, and lack of leaflet coaptation for restricted motion or erosion of the free edge in 13. Degenerative disease was the cause of mitral regurgitation in $80.8 \%$ of the patients, rheumatic disease was the cause in $9.6 \%$, endocarditis was the cause in $6.1 \%$, and ischemic disease was the cause in $2.3 \%$.

Results: Hospital mortality was $0.7 \%$, and the overall survival at 5 years was $94.4 \%$ $\pm 2.59 \%$. Thirteen patients required a reoperation ( 2 early postoperatively and 11 late during the follow-up), for an overall freedom from reoperation of $90.0 \% \pm$ $3.37 \%$ at 5 years. Freedom from reoperation was lower in patients with rheumatic valve disease and in patients who did not undergo an annuloplasty procedure.

Conclusions: The effectiveness and durability of the central double-orifice technique were assessed in this study. This type of repair can be a useful addition to the surgical armamentarium in mitral valve reconstruction.

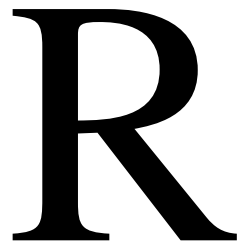

epair of a regurgitant mitral valve is superior to mitral valve replacement, with lower hospital mortality, longer survival, better preservation of ventricular function, fewer thromboembolic complications, and reduced risk of endocarditis. ${ }^{1}$ Therefore, it is desirable to extend the population of patients who can benefit from mitral valve reconstruction.

The most common cause of degenerative mitral regurgitation (MR) is a floppy (myxomatous) valve with segmental prolapse of the posterior leaflet. ${ }^{2}$ This lesion can be corrected by means of quadrangular resection of the prolapsing portion of the posterior leaflet, with highly reproducible and durable results. ${ }^{3}$ Other lesions, however, are associated with less-gratifying results, require more complex and surgically demanding techniques, or both, and many surgeons are hesitant to perform a reconstructive operation under these circumstances. For instance, correction of MR caused by anterior leaflet prolapse is less predictable than posterior leaflet repair, and the poor results obtained with anterior leaflet resection have led to other more complex and less reproducible techniques, such as chordal shortening, chordal transposition, and chordal replacement. ${ }^{4-8}$ Similarly, prolapse of both leaflets in severe myxomatous degeneration 
(Barlow disease) represents a challenging surgical problem requiring a number of different maneuvers directed toward the leaflets and the entire subvalvular apparatus. Prolonged aortic crossclamp times have been reported for the correction of bileaflet prolapse, ${ }^{9}$ and immediate and long-term results can be affected by the complexity of the surgical procedure. In the presence of an extensively calcified posterior anulus, decalcification is required to allow annular plication for conventional quadrangular resection, as described by el Asmar and colleagues, ${ }^{10}$ but this maneuver is potentially dangerous, time consuming, and not easily reproducible. Also, MR as a result of restricted leaflet motion caused by rheumatic or ischemic disease may represent a condition not easily amenable to valve repair by the conventional techniques.

Mitral valve reconstruction on the basis of the approximation of the free edge of the leaflets at the site of regurgitation (edge-to-edge technique) has been quite effective in the aforementioned complex situations. ${ }^{11-13}$ When the approximation of the free edge of the leaflets is carried out centrally, away from the commissural area, a double-orifice mitral valve is artificially created. In this article the effectiveness of the edge-to-edge technique resulting in a double-orifice mitral valve configuration is confirmed on the basis of a large body of experience, and the stability of the results over time is assessed.

\section{Methods \\ Patients}

From October 1992 through March 2000, of 902 consecutive patients with pure MR undergoing valve operations, 861 (95.5\%) underwent valve repair. In 260 patients regurgitation was corrected by the central double-orifice technique. We excluded 82 patients in whom the edge-to-edge suture was not placed in the central portion of the leaflets; that is, it was on either P1 or P3 scallops of the posterior leaflet at or near the commissure. There were 155 male and 105 female patients, with a mean age of $56 \pm 14.3$ years (range, 1779 years). At admission, 83 (31.9\%) patients were in New York Heart Association (NYHA) functional class I, 68 (26.1\%) were in class II, $104(40.0 \%)$ were in class III, and $5(1.9 \%)$ were in class IV. One hundred ninety-eight $(76.1 \%)$ patients were in sinus rhythm, and $62(23.9 \%)$ had preoperative atrial fibrillation.

The cause of the disease is shown in Table 1 . In the great majority of the cases, degenerative disease was the cause of MR.

Severe valve regurgitation was present in all patients. Table 2 shows the mechanism responsible for MR. The same mechanism of MR was common to different causes. For instance, in the group of patients with bileaflet prolapse, although the degenerative disease was by far the most prevalent cause, patients with endocarditis lesions were also represented, as were patients with rheumatic MR. More than half of the patients had bileaflet prolapse (in the majority of them, the valve showed the typical features of Barlow disease), and approximately one fourth had isolated anterior leaflet prolapse. Posterior leaflet prolapse was the cause of regurgitation in 31 patients. Although posterior leaflet lesions are usually treated by conventional quadrangular resection, the central double-orifice technique was adopted in 27 patients because of extensive posterior annular calcification. In the other 4 patients with posterior leaflet prolapse, the
TABLE 1. Cause of mitral insufficiency

\begin{tabular}{lrc}
\hline Cause & $\mathbf{n}$ & $\%$ \\
\hline Degenerative & 210 & 80.8 \\
Rheumatic & 25 & 9.6 \\
Endocarditis & 16 & 6.1 \\
Ischemic & 6 & 2.3 \\
Other* & 3 & 1.2 \\
Total & 260 & 100 \\
\hline
\end{tabular}

*Functional MR in dilated cardiomyopathy (2 patients) and amyloidosis (1 patient).

TABLE 2. Mechanism of mitral insufficiency

\begin{tabular}{lrr}
\hline Mechanism of MR & n & $\%$ \\
\hline Bileaflet prolapse & 148 & 56.9 \\
Anterior leaflet prolapse & 68 & 26.2 \\
Posterior leaflet prolapse & 31 & 11.9 \\
Lack of coaptation without prolapse & 13 & 5.0 \\
Restricted motion & 9 & \\
Free-edge erosion & 4 & \\
\hline
\end{tabular}

left atrium was small, and the central double-orifice technique was conveniently used to correct MR through the aortic root during aortic valve replacement. In the group of patients in whom the mechanism of MR was lack of leaflet coaptation without prolapse, restricted leaflet motion was due to ischemic heart disease in 6 patients and to rheumatic disease in 3 patients. In 4 patients erosion of the free edge of the leaflets as a result of endocarditis was responsible for MR.

In 44 patients severe and extensive calcification of the anulus was present.

Four patients had a previous cardiac operation: coronary artery bypass surgery (1 patient); correction of coarctation of the aorta (1 patient), aortic valve replacement (1 patient), and mitral valve repair with an annuloplasty ring (1 patient).

Left ventricular ejection fraction was above $45 \%$ in 242 $(93.0 \%)$ patients and below this level in 18 patients. Patients who underwent a central double-orifice valve repair in the context of the Batista operation were not included in this analysis.

\section{Surgical Technique}

The technique has been described before. ${ }^{11-13}$ In brief, a doubleorifice mitral valve is created by approximating the free edges of the leaflets at the site of regurgitation, usually with a running 4-0 polypropylene suture. In case of very thin leaflets, 1 or more Ushaped 5-0 polypropylene stitches reinforced with pledgets are used.

The operation is currently carried out through a conventional midline sternotomy during normothermic cardiopulmonary bypass with the use of intermittent cold-blood cardioplegia. The mitral valve is approached through the left atrium, with the incision done in the interatrial groove.

More recently, the operation has been performed through a minimally invasive approach by Port-Access cannulation (10 patients; Heartport, Inc, Redwood City, Calif) and robotic technology (3 patients). 


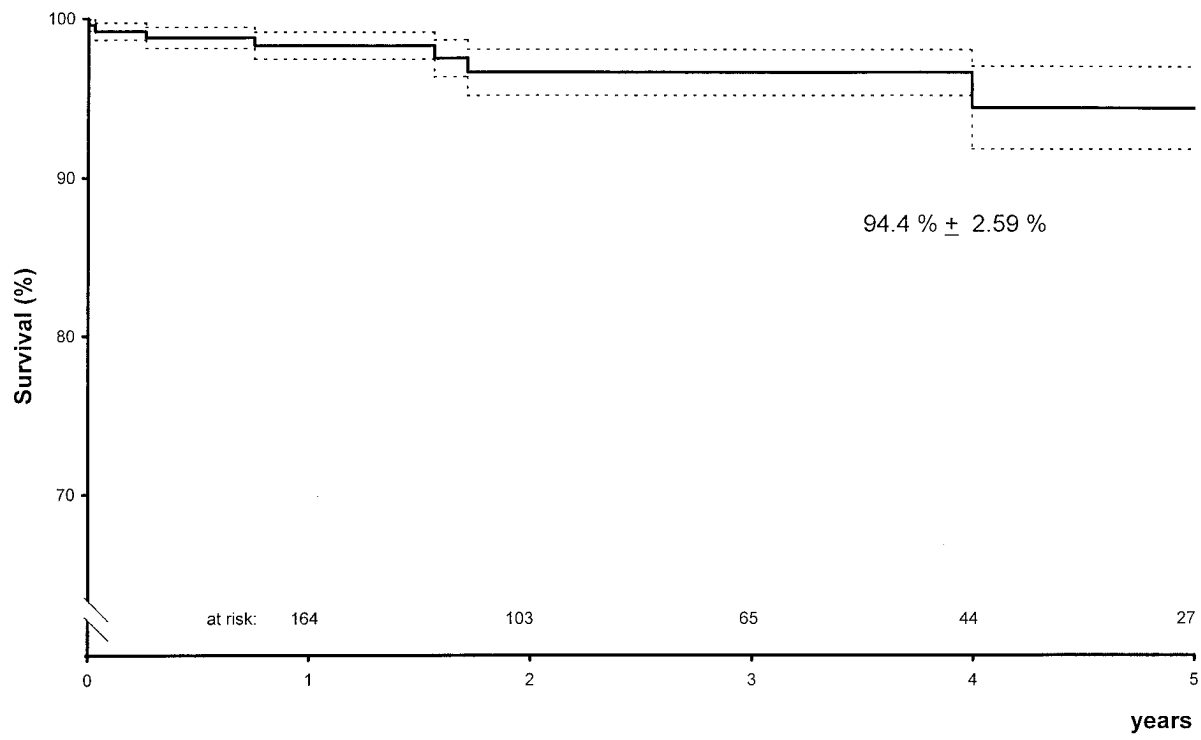

Figure 1. Overall survival. Dotted lines depict SE estimates for the mean actuarial survival curve.

An annuloplasty with or without a prosthetic ring was associated in $208(80.0 \%)$ patients; it was not carried out when the anulus was not dilated ( 8 patients) or in cases of severely calcified anulus (44 patients). In $83.5 \%$ of the patients, the central double-orifice technique alone was sufficient to correct MR, whereas in less than one fifth of the patients, additional reconstructive procedures (eg, leaflet resection, implantation of artificial chordae, patch repair of perforation, and chordal transposition) were concomitantly performed as indicated.

In all cases after reconstruction, the valve area was measured with Hegar dilators passed through the orifices: a global valve area of more than $2.5 \mathrm{~cm}^{2}$ was considered acceptable for "normal-size" patients. Competence was evaluated by means of forceful injection of saline solution into the left ventricle.

Other cardiac procedures were associated as needed: coronary artery bypass grafting (10 patients); radiofrequency ablation of atrial fibrillation ( 9 patients); tricuspid valve annuloplasty ( 7 patients); aortic valve replacement ( 9 patients); aortic valve repair (3 patients); correction of atrial septal defect (4 patients); and other operations (4 patients).

Mean cardiopulmonary bypass time and aortic crossclamp time were $54 \pm 14.9$ and $39 \pm 8.9$ minutes, respectively. Excluding patients undergoing associated cardiac procedures, mean cardiopulmonary bypass and ischemic times were $48 \pm$ 8.5 and $33 \pm 5.7$ minutes, respectively.

Patients in whom a prosthetic ring was implanted received short-term (3 months) anticoagulation. No long-term anticoagulation was prescribed, unless atrial fibrillation was present or a prosthetic aortic valve was also inserted.

\section{Follow-up}

Follow-up information was obtained for all hospital survivors and was $100 \%$ complete. The mean period of follow-up was $2.0 \pm 1.74$ years (range, 1 month to 7 years), for a cumulative follow-up of 529 patient-years. Data were collected either through outpatient visit or by telephone contact with the patient or the referring physician in the period ranging from April 1 to April 30, 2000.

\section{Statistical Analysis}

Data were analyzed with the statistical package JMP for Macintosh (SAS Institute, Inc, Cary, NC). Preoperative variables included in the models were age, sex, cause, mechanism of regurgitation, NYHA class, annuloplasty, annular calcification, associated aortic valve replacement, and associated coronary artery bypass grafting. The baseline characteristics and outcomes were compared by $\chi^{2}$ analysis for categorical data and $t$ tests for continuous variables. Survival and freedom from reoperation were analyzed with Kaplan-Meier actuarial methods. Comparison among groups was done according to the log-rank method. Outcomes were evaluated multivariately by stepwise logistic regression analysis. The variables included in the model were selected among those reaching a $P$ value of .25 or less at univariate analysis. Results are reported as means \pm standard deviation; for actuarial estimates, standard error is reported instead.

\section{Results \\ Mortality}

Two patients died in the hospital, for an overall $0.7 \%$ operative mortality. A 68-year-old woman submitted to mitral and aortic valve repair, who had a normal preoperative coronary angiogram, died of untreatable coronary spasm (angiographically documented), causing perioperative myocardial infarction in the first postoperative day. Another patient died 1 week postoperatively of right ventricular failure and subsequent multiple organ failure. Both patients had a competent nonstenotic mitral valve at echocardiography. There were 5 late deaths: 2 were noncardiac (cancer) in origin, and 3 were cardiac ( 2 sudden deaths and 1 for documented acute 


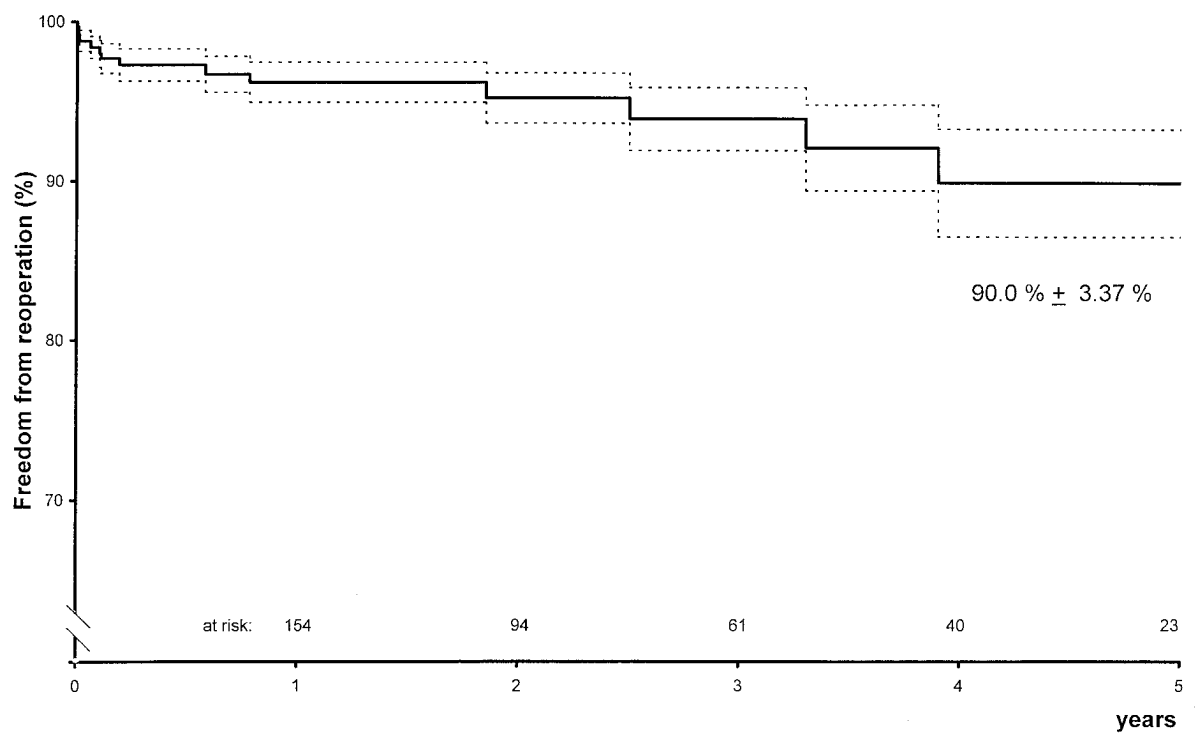

Figure 2. Overall freedom from reoperation. Dotted lines depict SE estimates for the mean actuarial freedom from the reoperation curve.

myocardial infarction). The actuarial overall survival at 5 years was $94.4 \% \pm 2.59 \%$ (Figure 1 ).

\section{Morbidity}

The postoperative course was quite smooth in most patients undergoing valve repair. Six patients required re-exploration for bleeding within 24 hours of the operation, 3 needed prolonged ( $>48$ hours) ventilatory and inotropic support, and 2 required pacemaker implantation within the hospital stay either for sick sinus syndrome (1 patient) or permanent atrioventricular block (1 patient). Systolic anterior motion of the anterior leaflet was never detected with echocardiography. After discharge, few morbid events were observed among hospital survivors. Three patients had new onset of congestive heart failure with a well-functioning mitral valve, 2 patients had endocarditis causing disruption of the mitral reconstruction and requiring reoperation, 1 patient had major gastrointestinal bleeding, and 1 patient experienced a cerebrovascular accident resulting from thromboembolism.

\section{Reoperation}

One patient required early reoperation for residual $\mathrm{MR}$, and 1 required early reoperation for mitral stenosis. In the latter case the atrioventricular obstruction was found at the subvalvular level at transesophageal echocardiography. The mechanism of stenosis was hypertrophy of the papillary muscles, with impingement in the orifices of the valve.

There were 11 late reoperations, for an overall freedom from reoperation of $90.0 \% \pm 3.37 \%$ at 5 years (Figure 2 ). The cause of reoperation was recurrent severe MR, except in 1 case, in which the cause was severe hemolysis as a result of partial detachment of the prosthetic ring and trivial MR. Disruption of the edge-to-edge suture exclusively occurred in the 2 patients with endocarditis. In 8 patients a new prolapse of the valve was the cause of MR, either because of new chordal rupture or chordal elongation. In only 2 patients was rerepair of the valve carried out. No patients required late reoperation for mitral valve stenosis. Freedom from reoperation was $91 \% \pm 3.7 \%$ at 5 years in the degenerative disease group, $72 \% \pm 14.5 \%$ in the rheumatic group, and $93 \% \pm 6.7 \%$ in the endocarditis group. No patient with an ischemic cause of MR required reoperation during the follow-up period ( $P=.06$, Figure 3$)$.

Freedom from reoperation in the patients who underwent an annuloplasty procedure was $92 \% \pm 3.4 \%$, whereas it was $70 \% \pm 15.0 \%$ in those who did not $(P=.02$, Figure 4$)$.

Risk factors for reoperation, as determined by univariable and multivariable analysis, are reported in Table 3.

\section{Functional Status}

Functional status at latest follow-up was obtained in 253 patients: 173 patients $(68.3 \%)$ were in NYHA class I; 63 $(24.9 \%)$ were in class II; $15(5.9 \%)$ were in class III; and 2 $(0.7 \%)$ were in class IV. No important mitral valve dysfunction was documented in patients with persisting symptoms.

\section{Discussion}

The techniques of mitral valve repair developed and popularized by Carpentier ${ }^{4}$ are the basis of the conservative approach to mitral valve surgery and are extensively used in our institution. The central double-orifice technique has been essentially reserved for patients with severe MR 


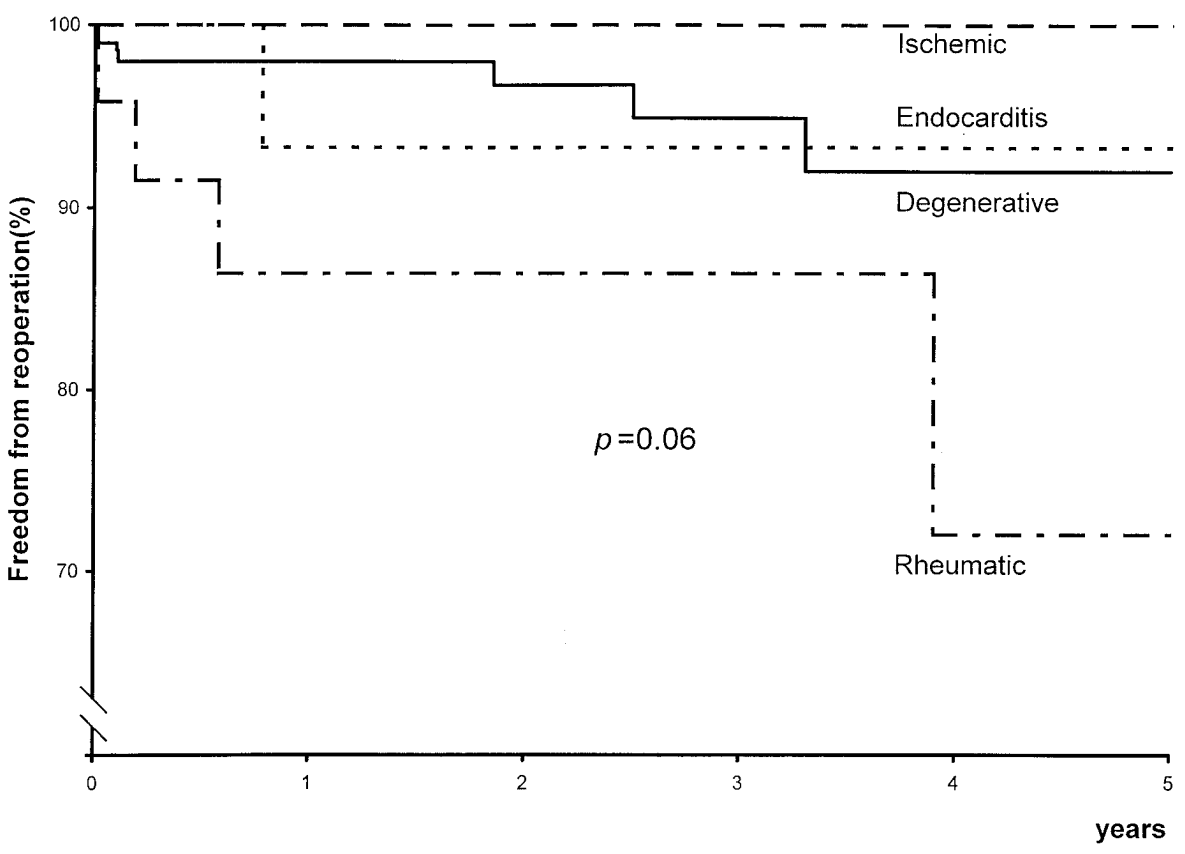

Figure 3. Freedom from reoperation according to cause.

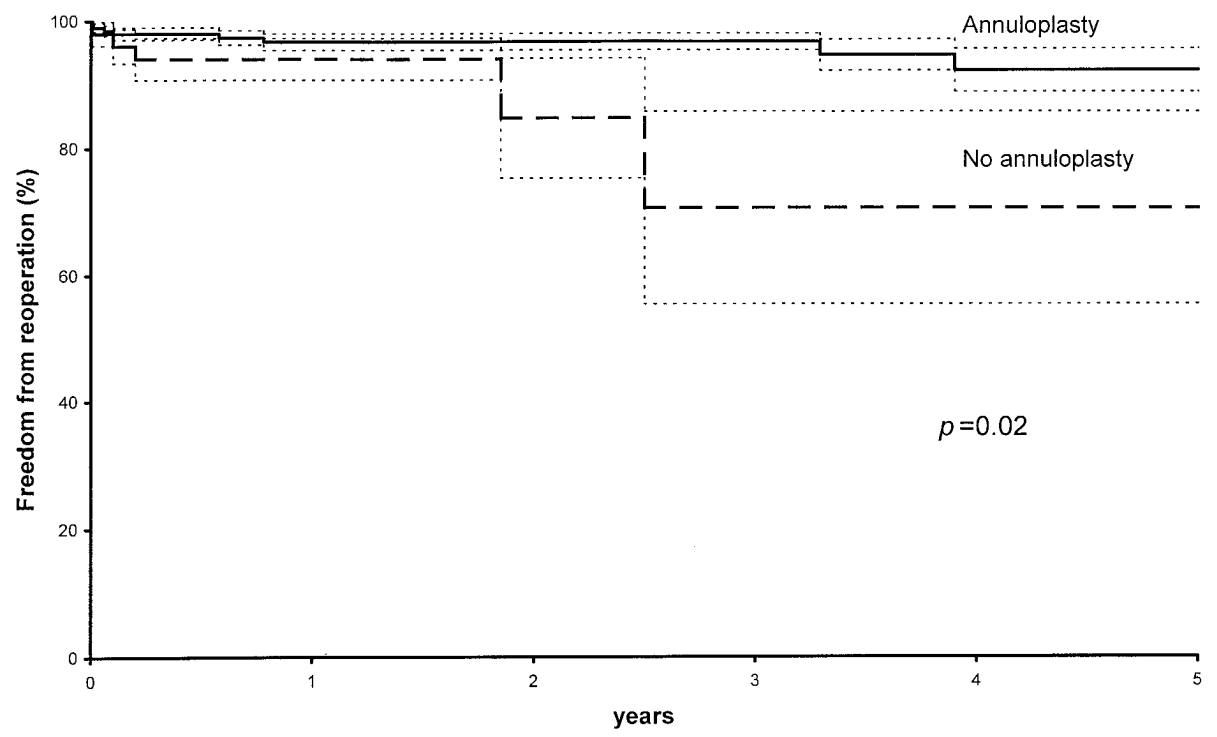

Figure 4. Freedom from reoperation in patients who received an annuloplasty procedure versus those who did not. Dotted lines depict SE estimates for the actuarial curves.

caused by complex lesions requiring demanding (although effective) surgical techniques for correction or with an expected lower probability of successful repair, namely, prolapse of both leaflets, prolapse of the anterior leaflet, or prolapse of the posterior leaflet in the presence of an extensively calcified anulus. Also, a small number of patients with restricted leaflet motion caused by rheumatic or ischemic disease were conveniently treated with the central double-orifice technique, as were patients with erosion of the free edge of the leaflets. After the introduction of the central double-orifice technique, the percentage of patients with pure MR treated with mitral valve reconstruction is approximately $95 \%$. Many patients in this series underwent the operation when they were still relatively asymptomatic 
or with few symptoms, despite severe MR. This strategy, which is consistent with the concept that early intervention is associated with a positive effect on the natural history of the disease, ${ }^{14}$ reflects our confidence in the central doubleorifice technique as a method that can provide an effective and durable repair, even in the presence of complex lesions. Along with early operation, a minimally invasive approach is now often requested, particularly by young women, who are understandably reluctant to undergo a major operation with no or few symptoms. On the basis of our limited experience, even complex lesions, such as bileaflet prolapse in Barlow disease, can be effectively corrected with the central double-orifice technique through a minithoracotomy with the Heartport system for cardiopulmonary bypass. The central double-orifice procedure can be carried out in a short period of time, as demonstrated by the duration of cardiopulmonary bypass and aortic crossclamping time in this series. This is particularly convenient when associated procedures are needed and in patients with poor preoperative conditions or with advanced left ventricular dysfunction. The central double-orifice repair is technically simple, but careful evaluation of the mitral valve is always mandatory, and considerable judgment is required in selecting the right site for the approximation of the leaflets and the appropriate extension of the suture. The surgeon should aim at the complete elimination of the MR, minimizing the reduction of the valve area. Inadequate application of the technique may result either in residual MR or in mitral stenosis. When the leaflets are particularly redundant, as in Barlow disease, the suture should also aim at the reduction of the height of the leaflets to prevent systolic anterior movement of the anterior leaflet. The technical details of the central doubleorifice repair as a standardized approach to treat MR in the setting of Barlow disease have been published previously. ${ }^{13}$

In the present study, early and late mortality were totally unrelated to the technique of repair. The incidence of early and late complications was low, as in the other series of patients treated with mitral valve reconstruction. Left ventricular dysfunction was the main determinant of the persistence of symptoms in the presence of a well-functioning valve. Considering the type of lesions treated in this series, freedom from reoperation at 5 years was satisfactory. Also, with the central double-orifice technique, the reoperationfree survival was lower in the group of patients with rheumatic disease, a finding already reported by other authors. ${ }^{4,15}$ Because of the small number of patients with ischemic MR in the present study, the role of the central doubleorifice technique in this difficult setting is not clearly defined. When an annuloplasty was not carried out, freedom from reoperation was significantly lower. Because an annuloplasty was mostly avoided in patients with an extensively calcified anulus, we can conclude that the central doubleorifice repair, although attractive in this setting, is not a
TABLE 3. Risk factors for reoperation

\begin{tabular}{ll}
\hline Variable tested & $\boldsymbol{P}$ value \\
\hline Univariable analysis & .35 \\
Age & .1 \\
Sex & .59 \\
NYHA class & .01 \\
Cause of MR & .12 \\
Mechanism of MR & .54 \\
Annular calcification & .089 \\
Annuloplasty & .45 \\
Associated CABG & .43 \\
Associated AVR & \\
Multivariable analysis (logistic regression)* & .19 \\
Sex & .36 \\
Cause of MR & .61 \\
Mechanism of MR & .23 \\
Annuloplasty & \\
\hline CABG, Coronary artery bypass grafting; AVR, aortic valve replacement. \\
*Only variables with a P value of less than .25 at univariable analysis were \\
considered.
\end{tabular}

panacea and can be associated with suboptimal results. A limitation of this study is that the echocardiographic data obtained during the period of follow-up are not reported. This is due to the fact that the majority of the patients were referred to us from remote geographic areas, and therefore the echocardiographic examinations were performed locally, inevitably with a large variety of criteria of interpretation.

In conclusion, the present study confirms the favorable results obtained with the central double-orifice technique and also demonstrates the durability of the repair at least up to 5 years of follow-up. We are aware that similar results can be obtained with other techniques of repair evolved through the years, and therefore we propose the central doubleorifice technique as an effective alternative approach that can be a useful addition to the surgical armamentarium in mitral valve reconstruction.

\section{References}

1. Yun KL, Miller DC. Mitral valve repair versus replacement. Cardiol Clin. 1991;9:315-27.

2. Olson LJ, Subramanian R, Ackermann DM, Orszulak TA, Edwards WD. Surgical pathology of the mitral valve: a study of 712 cases spanning 21 years. Mayo Clin Proc. 1987;62:22-34.

3. Gillinov AM, Cosgrove DM, Blackstone EH, Diaz R, Arnold JH, Lytle BW, et al. Durability of mitral valve repair for degenerative disease. $J$ Thorac Cardiovasc Surg. 1998;116:734-43.

4. Carpentier A. Cardiac valve surgery. The "French correction." $J$ Thorac Cardiovasc Surg. 1983;86:323-7.

5. Salati M, Moriggia S, Scrofani R, Santoli C. Chordal transposition for anterior mitral prolapse: early and long-term results. Eur $J$ Cardiothorac Surg. 1997;11:268-73.

6. Smedira N, Selman R, Cosgrove DM, McCarthy PM, Lytle BW, Taylor PC, et al. Repair of anterior leaflet prolapse: chordal transfer is superior to chordal shortening. J Thorac Cardiovasc Surg. 1996;112:287-91.

7. David TE. Replacement of chordae tendineae with expanded polytetrafluoroethylene sutures. J Card Surg. 1989;4:286-90. 
8. Zussa C, Polesel E, Rocco F, Valfrè C. Artificial chordae in the treatment of anterior mitral leaflet pathology. Cardiovasc Surg. 1997;5:125-8.

9. Sousa Uva M, Dreyfus G, Rescigno G, al Aile N, Mascagni R, La Marra $\mathrm{M}$, et al. Surgical treatment of asymptomatic and mildly symptomatic mitral regurgitation. J Thorac Cardiovasc Surg. 1996;112:1240-8.

10. el Asmar B, Acker M, Couetil JP, Perier P, Dervanian P, Chauvaud S, et al. Mitral valve repair in the extensively calcified mitral valve annulus. Ann Thorac Surg. 1991;52:66-9.

11. Fucci C, Sandrelli L, Pardini A, Torracca L, Ferrari M, Alfieri O. Improved results with mitral valve repair using new surgical techniques. Eur J Cardiothorac Surg. 1995;9:621-6.

12. Maisano F, Torracca L, Oppizzi M, Stefano PL, D'Addario G, La Canna G, et al. The edge-to-edge technique: a simplified method to correct mitral insufficiency. Eur J Cardiothorac Surg. 1998;13:240-5.

13. Maisano F, Schreuder JJ, Oppizzi M, Fiorani B, Fino C, Alfieri O. The double-orifice technique as a standardized approach to treat mitral regurgitation due to severe myxomatous disease: surgical technique. Eur J Cardiothorac Surg. 2000;17:201-5.

14. Ling LH, Enriquez-Sarano M, Seward JB, Tajik AJ, Schaff HV, Frye RL. Clinical outcome of mitral regurgitation due to flail leaflet. $N$ Engl J Med. 1996;335:1417-23.

15. Yau TM, El-Ghoneimi YA, Armstrong S, Ivanov J, David TE. Mitral valve repair and replacement for rheumatic disease. $J$ Thorac Cardiovasc Surg. 2000;119:53-60.

\section{Discussion}

Dr D. Craig Miller (Stanford, Calif). Congratulations, Dr Maisano, for a fine presentation. You have represented Dr Alfieri's group well at previous meetings, and today is no exception. After having just heard the world's largest experience from the citadel of the "Alfieri stitch," as we call it-although out of modesty Professor Alfieri terms it the "edge-to-edge technique"-I thought it would be helpful for the audience to take you through the last 5 years of the literature with respect to what we have learned about this technique. The original 1995 Fucci paper showed that the edge-to-edge repair was employed in 35 cases out of 299, or only $12 \%$ of their repairs. In this early learning phase it probably was used as a "bail-out" maneuver often, that is, where after a conventional repair persistent problems such as residual anterior leaflet prolapse were identified and the leaflets were therefore sutured together. Then, at the 1997 EACTS meeting in Copenhagen your group had applied the edge-to-edge technique in $28 \%$ of 432 patients. In your overall experience presented today, this fraction is now up to $35 \%$ of mitral repairs; perhaps most importantly, it was the only procedure you performed on the leaflets per se in $75 \%$ of these Alfieri patients. Now, why is that? You are obviously gaining more confidence in this procedure, but some of this increased usage is due to the fact that you are doing an Alfieri stitch in a growing subpopulation of young patients with Barlow's syndrome. You presented at the EACTS meeting in Glasgow last September that all you do is a 2 to $3-\mathrm{cm}$ long running stitch between the billowing central portions of the leaflets in these Barlow's cases without any leaflet resection. Should we really abandon leaflet resection and Carpentier's original techniques and just do this? Or, conversely, is your $75 \%$ usage of only the edge-to-edge technique without other leaflet procedures due to this large minority, possibly a majority, of Barlow patients?

Dr Maisano. Thank you, Dr Miller. We are now applying the double-orifice technique to an increasing percentage of patients undergoing valve repair at our institution. In the last year, about $35 \%$ of the valve-repair operations included the edge-to-edge technique, largely because our hospital has gained experience in the treatment of Barlow disease, and it has become the referring center for this condition in our country. On the basis of our experience, leaflet resection is not necessary in most cases of leaflet prolapse when it is an integrated part of a severe form of Barlow disease. In this case we simply rely on a single running suture in the middle of the leaflets; this single maneuver is effective in most cases of bileaflet prolapse, even when one leaflet is flail.

Dr Miller. You have proven that it does restore competence in patients with Barlow's, but how does it reduce the length of the elongated chordae and leaflet tissue? You talked about that in your paper published in The European Journal of Cardio-Thoracic Surgery a couple of months ago, but please tell us how big these bites are you taking. You say "big bites" of the leaflets, but they must be real "Texas-size bites" as Dr Cooley would say, that is, 1$\mathrm{cm}$ to $2-\mathrm{cm}$ bites, to reduce the excessive overall length of the chordae and billowing leaflets.

Dr Maisano. I think there are 2 possible answers for this intriguing question. One is that by taking big bites, the height of the leaflets is reduced, and the tissue redundancy is diminished; moreover, the stitch is placed at the limit of the rough zone to force coaptation in this physiologic area. A second explanation can be related to the dynamics of valve closure: the presence of a central stitch implies coaptation early in the systolic phase, when the left ventricular volume is higher and the length of the subvalvular apparatus matches the long axis of the ventricle.

Dr Miller. Does that mean that the postoperative echo shows you actually are not eliminating the persistent hooding and billowing characteristics of these Barlow leaflets, but the valve no longer leaks?

Dr Maisano. No, we usually see no billowing after the doubleorifice technique, with the coaptation level well below the annular plane, whereas in Barlow disease it is usually above it before the repair. However, there are a few cases with residual billowing and without leak.

Dr Miller. Then perhaps Houdini is still alive and lives in Milano, because somehow you are eliminating a lot of excess tissue in these Barlow patients. I guess I will have to visit your unit to understand completely what happens to all the surfeit of chordal and leaflet tissue.

This is a little disappointing to me because I believed your Alfieri stitch would be a great trick where you had an extensively and severely calcified posterior mitral anulus that you do not want to decalcify, but are you telling us today in those 50 cases or so where you did not use a ring for various reasons that you have more failures or recurrence of MR?

Dr Maisano. We observed that the nonuse of the ring is a risk factor for reoperation; however, I should point out that patients undergoing the double-orifice technique are part of a selected population at high risk either of valve repair failure or of perioperative adverse outcome. In patients with a severely and extensively calcified anulus, another possible approach is the annular decalcification, which we believe is, at least in our hands, a very risky procedure, especially in older patients. We decided to approach this situation with the double-orifice technique whenever possible. Unfortunately, in most of these patients, the leaflet lesions are associated with some degree of annular dilatation, and we leave this anomaly untreated by solely doing a double-orifice procedure. Although soon after cardiopulmonary bypass discontinuation, 
there was no one patient with MR of more than mild severity, in some cases it has progressed, and it has been the reason for reoperation in some patients in our series.

Dr Miller. Does that mean today you are decalcifying the atrioventricular groove under the posterior anulus?

Dr Maisano. No, we still think that this is a very dangerous maneuver, and we try to avoid it. However, we are aware of the risk of recurrent MR in these patients.

Dr Miller. I agree it can be a very dangerous maneuver, especially in the elderly, and should be undertaken only in carefully selected circumstances.

My next point is good news/bad news situation. What do you think of the cardiologists taking your Alfieri stitch to the catheterization laboratory and doing mitral valve repairs outside the surgical arena? Has any of this been done yet it Italy? It is now rumored to have been done in Brazil, Eastern Europe, and even California.

Dr Maisano. I am aware that there is a program at Columbia University about this topic, but we do not have direct experience with it. A device able to staple together 2 leaflets can be designed, but some limitations still exist to its introduction in clinical practice. First of all, it is not easy to decide the site of stapling and to control its position. Second, an annuloplasty cannot be added to the procedure, and this has to be considered mandatory in most cases.

Dr Miller. Let's hope that will stop, or at least delay, our cardiology colleagues, but I am not as sanguine that it will.

Now, your old colleagues from Brescia, after you and Ottavio Alfieri moved to Milano, will be presenting a paper at this year's American Heart Association meeting showing that in patients with anterior leaflet prolapse, one of the predictors of valve repair failure is poor left ventricular systolic function. I presume these data were obtained from your original patients operated upon in Brescia. We all used to think, based on Theo Art's theoretical models from over 25 years ago, that where you sew the leaflets together is a low stress point. Do you really think that is so in dilated, poorly contracting ventricles? We have some animal data where we did the Alfieri procedure with a strain transducer which show that it is, indeed, a low-stress point under basal or normal resting conditions, but becomes a high-stress point if you induce acute left ventricular ischemia and the ventricle and mitral anulus dilate. What do you expect your results will be in patients with these bad ventricles?

Dr Maisano. This is a very stimulating question. In our experience we did not find any correlation between left ventricular function and failure of the repair, but you pointed out that the stress on the leaflets is higher in the presence of ventricular dysfunction, and this may have an influence on the strain on the double-orifice suture. However, we use an annuloplasty ring in all cases of cardiomyopathy, and this procedure reduces the stress on the leaflets.
Dr Miller. My final question relates to that point-ischemic MR where morphologically normal leaflets can leak severely due to geometric changes in the subvalvular apparatus and left ventricle. You now have applied the edge-to-edge technique in 14 patients with ischemic MR according to your manuscript. What do you think the role of the Alfieri stitch is in patients with ischemic $\mathrm{MR}$, with or without an annuloplasty ring?

Dr Maisano. I believe the edge-to-edge technique has an important role in the treatment of ischemic MR. However, MR is an almost unknown disease, and any procedure has to be applied to the basis of the exact knowledge of the mechanism of regurgitation. For instance, in case of papillary muscle dysfunction, a paracommissural edge-toedge repair, associated with ring annuloplasty to reduce the tethering effect, is a fast and effective solution. In other patients, when the regurgitant jet is central, a double-orifice repair can be done, but we still do not know whether this technique should be alternative or complementary to undersized annuloplasty. I believe this is one of the most stimulating issues in cardiac surgery today, and our group is dedicated to the research of the insights of this disease.

Dr Miller. Therefore, you are saying you would not rely on an Alfieri stitch alone? It sounds to me that what you are describing is just a posteromedial commissuroplasty.

Ischemic MR conceivably could be the biggest application for this procedure, which otherwise most surgeons still consider to be just a "bail-out" method.

Finally, I would like to compliment you where you caution us in your paper that you do not really have comprehensive late echo follow-up on your patients and you simply do not know how well these repaired valves are functioning. Could you just give us your personal subjective impression of the degree of residual MR in those patients who have been studied postoperatively in Milano?

Dr Maisano. We decided not to include the Doppler echocardiographic data in our article because we do not have a sufficient number of examinations available. As I said before, most of our patients come from a broad area, throughout Italy, and follow-up in our department is difficult. We collected data from about 150 patients studied at our echocardiography laboratory. What we have seen is that all patients have significant reduction of the valve area after the repair, as expected. The mitral valve area goes to a mean of about $3.5 \mathrm{~cm}^{2}$ from a preoperative value of about $9 \mathrm{~cm}^{2}$; this reduction does not tend to increase over time.

Dr Miller. In those 150 patients, what about persistent or recurrent MR?

Dr Maisano. Of the subgroup with a postoperative long-term Doppler echocardiographic study performed at our institution, we have 15 patients with residual MR grade $2 / 4,7$ with grade $3 / 4$, and 2 with severe MR. Among these patients are included those who underwent reoperation at our institution. 